\title{
Molecular epidemiology of Japanese encephalitis virus circulating in South Korea, 1983-2005
}

\author{
Seok-Min Yun, Jung Eun Cho, Young-Ran Ju, Su Yeon Kim, Jungsang Ryou, Myung Guk Han, Woo-Young Choi and \\ Young Eui Jeong*
}

\begin{abstract}
We sequenced the envelope (E) gene of 17 strains of the Japanese encephalitis virus (JEV) isolated in South Korea in 1983-2005 and compared the sequences with those from previously reported strains. Our results show the remarkable genetic stability of the $\mathrm{E}$ gene sequence in Korean JEV strains. Five pairs of $\mathrm{E}$ gene sequences from 10 Korean strains were identical, despite geographical differences and a maximum five-year time span. Sequence comparisons with other Asian strains revealed that the Korean strains are closely related to those from China, Japan, and Vietnam. Genotype 3 strains were predominant in Korea before 1993, when genotype 1 strain K93A07 was first isolated. The two genotypes were detected simultaneously in 1994 but since then, only genotype 1 has been isolated in South Korea. Thus, the genotype change occurred according to the year of isolation rather than the geographical origin.
\end{abstract}

\section{Findings}

Japanese encephalitis virus (JEV) is a mosquito-borne flavivirus (genus Flavivirus, family Flaviviridae), which causes acute viral encephalitis in humans. Approximately 30,000-50,000 cases, with 10,000 deaths, are reported annually throughout Asia [1]. The JEV genome is a positive-sense, single-stranded RNA molecule, approximately $11 \mathrm{~kb}$ in length. The polyprotein is processed into three structural proteins, the capsid (C), membrane (M), and envelope (E) proteins, and seven nonstructural proteins, NS1, NS2A, NS2B, NS3, NS4A, NS4B, and NS5 [2].

Generally, RNA viruses have intrinsically high mutation rates and consequently greater potential for rapid evolution than the DNA viruses [3]. Many studies have revealed the phylogenetic relationships among the JEV strains. Although full-genome sequences provide the most reliable information, it takes several weeks to fully sequence a strain and an enormous computing capacity is required for the analysis of large sequences. Therefore, much shorter sequences from various genes are typically evaluated as phylogenetic markers. Historically, 3-4 JEV genotypes have been proposed based on short sequences (198 nt, $240 \mathrm{nt}$, or $280 \mathrm{nt}$ ) in the C/prM region [4-6], but

\footnotetext{
* Correspondence: sokdu@nih.go.kr

1 WHO Japanese Encephalitis Regional Reference Laboratory for the Western Pacific Region/Division of Arboviruses, National Institute of Health, Korea Centers for Disease Control and Prevention, Seoul, Republic of Korea Full list of author information is available at the end of the article
}

such short sequences are insufficient to identify exact relationships. Therefore, the complete E gene $(1,500 \mathrm{nt})$ is preferred as a marker and 4-5 genotypes have been reported in phylogenetic analyses [7-10]. To date, the molecular epidemiology of JEV strains has been well studied in Asian countries, including China, Japan, India, Taiwan, Thailand, and Vietnam [6,11-14]. However, the molecular characterization of the Korean strains, including their genetic diversity, has not been well documented. Although over $100 \mathrm{JEV}$ strains have been isolated during extensive mosquito surveillance since 1975, most of them have been lost, without further study. To date, only three strains have been fully sequenced: K87P39, K94P05, and KV1899 [15-17]. However, the C/prM or E genes of other strains, such as K82P01, K91P55, and K93P05, have been sequenced $[18,19]$.

Previous studies have only dealt with a few Korean strains isolated before 1999, and more recent strains must be analyzed to fully characterize the molecular epidemiology of JEV in South Korea. In this study, we sequenced the complete $\mathrm{E}$ genes of 17 Korean JEV strains isolated between 1983 and 2005 and analyzed their genetic variation and their relationships to other Asian strains.

Since 1975, the Korea National Institute of Health has annually checked JEV activity from vector mosquitoes collected between July and September in nine provinces of South Korea (Figure 1). Black-light traps were operated 
once a week in cattle sheds and the mosquitoes were identified morphologically and categorized to the species level. Only Culex tritaeniorhynchus mosquitoes (the major JEV vector in Korea) were processed for virus isolation, using suckling mice as described previously [18]. Seventeen strains from among the JEV strains isolated in South Korea in 1983-2005 were initially characterized in the present study (Table 1). Viral RNA was extracted from the stocks of each virus using the QIAamp Viral RNA Mini Kit (Qiagen, Valencia, CA, USA). The purified RNA was used as the template for cDNA synthesis using the SuperScript ${ }^{\text {tw }}$ III first-strand synthesis system (Invitrogen, Carlsbad, CA, USA) with primer JE-2623AS (NS1 region, 5'-GCTTTGTGGACGATCTTCGC-3'), according to the manufacturer's instructions. The synthesized cDNA was then used for PCR amplification with AccuPrime $^{\text {Tm }} P f x$ DNA polymerase (Invitrogen) and primers JE-723 S (prM/M region, 5'-CGGACCAGGCATTCCAA-3') and JE-2623AS. The primers were designed according to the consensus sequences of three Korean JEV strains (K94P05, K87P39, and KV1899). The amplified products $(1.9 \mathrm{~kb})$ were purified and sequenced using the ABI PRISM BigDye Terminator Cycle Sequencing Kit and an ABI $3730 \times 1$ sequencer (Applied Biosystems, Foster City, CA, USA) at Macrogen (Seoul, Korea). The nucleotide sequences of the $E$ genes (1,500 nt) were compared with those of other JEV strains representing each genotype and different geographic regions. A total of $86 \mathrm{E}$ gene sequences were initially collected and 29 strains representing each country and genotype were finally selected (Table 2). A multiple alignment was generated with the ClustalX 2.0.11 program [20] and the percentage similarities between the aligned sequences were calculated using the MegAlign program implemented in the Lasergene software (DNASTAR, Madison, WI, USA). Phylogenetic analyses based on the $\mathrm{E}$ gene were performed with the neighbor-joining (NJ) and maximum likelihood (ML) methods using MEGA 4.0 [21] and TREE-PUZZLE 5.2 [22], respectively. The E gene sequence of the Murray Valley encephalitis virus (MVEV) was used as the outgroup (GenBank accession no. NC_000943). For the NJ tree, the Tamura-Nei model was used to compute the genetic distances, and the reliability of the tree was tested by bootstrap analysis with 1,000 replications. For the ML

Table 1: Details of 22 strains of JEV from South Korea*

\begin{tabular}{|c|c|c|c|c|}
\hline Strain & Year & Source & Location & Accession no. \\
\hline K82P01 & 1982 & Culex tritaeniorhynchus & Youngkwang & U34926 \\
\hline K83Р34 & 1983 & Culex tritaeniorhynchus & IU & FJ938231 \\
\hline K83P44 & 1983 & Culex tritaeniorhynchus & IU & FJ938232 \\
\hline K84A071 & 1984 & Culex tritaeniorhynchus & IU & FJ938224 \\
\hline K87A07 & 1987 & Culex tritaeniorhynchus & IU & FJ938225 \\
\hline K87A071 & 1987 & Culex tritaeniorhynchus & IU & FJ938226 \\
\hline K87P39 & 1987 & Culex tritaeniorhynchus & Wando & U34927 \\
\hline K88A07 & 1988 & Culex tritaeniorhynchus & IU & FJ938227 \\
\hline K88A071 & 1988 & Culex tritaeniorhynchus & IU & FJ938228 \\
\hline K89A07 & 1989 & Culex tritaeniorhynchus & IU & FJ938229 \\
\hline K91P55 & 1991 & Culex tritaeniorhynchus & Wando & U34928 \\
\hline K93A07 & 1993 & Culex tritaeniorhynchus & IU & FJ938230 \\
\hline K94A07 & 1994 & Culex tritaeniorhynchus & IU & FJ938216 \\
\hline K94A071 & 1994 & Culex tritaeniorhynchus & IU & FJ938217 \\
\hline K94P05 & 1994 & Culex tritaeniorhynchus & Wando & U34929 \\
\hline K95A07 & 1995 & Culex tritaeniorhynchus & IU & FJ938218 \\
\hline K96A07 & 1996 & Culex tritaeniorhynchus & IU & FJ938219 \\
\hline KV1899 & 1999 & Pig serum & Gyeonggi & AY316157 \\
\hline K01-GN & 2001 & Culex tritaeniorhynchus & Gyeong-Nam & FJ938220 \\
\hline K01-JB & 2001 & Culex tritaeniorhynchus & Jeon-Buk & FJ938221 \\
\hline K01-JN & 2001 & Culex tritaeniorhynchus & Jeon-Nam & FJ938222 \\
\hline K05-GS & 2005 & Culex tritaeniorhynchus & Gunsan & FJ938223 \\
\hline
\end{tabular}

* Five isolates sequenced previously are indicated in boldface type.

IU: information unavailable. 
Table 2: Details of 29 JEV strains compared with Korean strains

\begin{tabular}{|c|c|c|c|c|c|}
\hline Strain & Year & Location & Source & Genotype & Accession no. \\
\hline $\mathrm{Fu}$ & 1995 & Australia & Human serum & 2 & AF217620 \\
\hline P3 & 1949 & China & Human brain & 3 & AY243844 \\
\hline YN & 1954 & China & Human brain & 3 & AY243838 \\
\hline SA 14 & 1954 & China & Mosquito & 3 & U14163 \\
\hline YN79-Bao83 & 1979 & China & Mosquito & 1 & DQ404128 \\
\hline YN86-B8639 & 1986 & China & Mosquito & 1 & DQ404133 \\
\hline $\mathrm{SH}-53$ & 2001 & China & Mosquito & 1 & AY555757 \\
\hline SH03-124 & 2003 & China & Mosquito & 1 & DQ404100 \\
\hline $\mathrm{SH} 04-3$ & 2004 & China & Mosquito & 3 & DQ404105 \\
\hline SH17M-07 & 2007 & China & Mosquito & 1 & EU429297 \\
\hline GP78 & 1978 & India & Human brain & 3 & AF075723 \\
\hline JKT5441 & 1981 & Indonesia & Mosquito & 2 & U70406 \\
\hline JKT7003 & 1981 & Indonesia & Mosquito & 4 & U70408 \\
\hline JKT9092 & 1981 & Indonesia & Mosquito & 4 & U70409 \\
\hline Nakayama & 1935 & Japan & Human brain & 3 & U70413 \\
\hline $\mathrm{JaOH} 0566$ & 1966 & Japan & Human brain & 3 & AY029207 \\
\hline JaOArS1186 & 1986 & Japan & Mosquito & 3 & AB028262 \\
\hline JaOArK5990 & 1990 & Japan & Unknown & 3 & AB028268 \\
\hline Ishikawa & 1994 & Japan & Pig & 1 & AB051292 \\
\hline JaNAr0990 & 1990 & Japan & Mosquito & 3 & AY427797 \\
\hline JaNAr32-04 & 2004 & Japan & Mosquito & 1 & FJ185151 \\
\hline PhAn1242 & 1984 & Philippines & Pig serum & 3 & U70417 \\
\hline B1065 & 1983 & Thailand & Pig blood & 2 & U70388 \\
\hline ThCMAr6793 & 1993 & Thailand & Mosquito & 1 & D45363 \\
\hline H49778 & 1987 & Sri Lanka & Human brain & 3 & U70395 \\
\hline VN207 & 1986 & Vietnam & Human brain & 3 & AY376461 \\
\hline VN50 & 1989 & Vietnam & Human brain & 3 & AY376463 \\
\hline VN78 & 2002 & Vietnam & Mosquito & 1 & AY376467 \\
\hline Muar & 1952 & Singapore & Human brain & 5 & [30] \\
\hline
\end{tabular}

tree, the HKY85 evolutionary model of nucleotide substitution was used to build the tree based on the complete $\mathrm{E}$ gene. The statistical significance of each internal branch of the tree was indicated as a quartet puzzling $(\mathrm{QP})$ value. Other parameters for the ML tree are available upon request. All the trees were produced with the MEGA 4.0 software.

Twenty-two Korean JEV strains showed minimal sequence similarities (uncorrected p-distances) of $87.3 \%$ and $96.2 \%$ at the nucleotide and amino acid sequence levels, respectively (Figure 2). Except for K82P01 and K91P55 strains, Korean JEV strains were divided into two groups, genotypes 1 and 3 . The nucleotide sequence divergence within the genotypes were only $0.3-1.7 \%$ (mean $1.1 \%$, genotype 1 ) and $0.1-2.7 \%$ (mean $1.5 \%$, geno- type 3), respectively. The sequence divergence between the two genotypes was $11.5 \%-12.7 \%$ (mean $12.0 \%$ ). K82P01 showed nucleotide divergences of 9.5\%-9.8\% from the genotype 1 strains and 3.8\%-4.5\% from the genotype 3 strains. K91P55 showed nucleotide divergences of $5.2 \%-5.9 \%$ from genotype 1 and $7.6-8.2 \%$ from genotype 3.

The E gene sequences of the Korean JEV strains showed remarkable genetic stability. Five pairs of E gene sequences from 10 Korean strains (K83P34 and K88A07, K84A071 and K87A071, K93A07 and K96A07, K94A07 and K95A07, and K01JN and K01-JB) were identical, despite differences in their geographic distributions and the maximum five-year time span. This genetic stability in JEV was also detected in strains from Taiwan, China, 


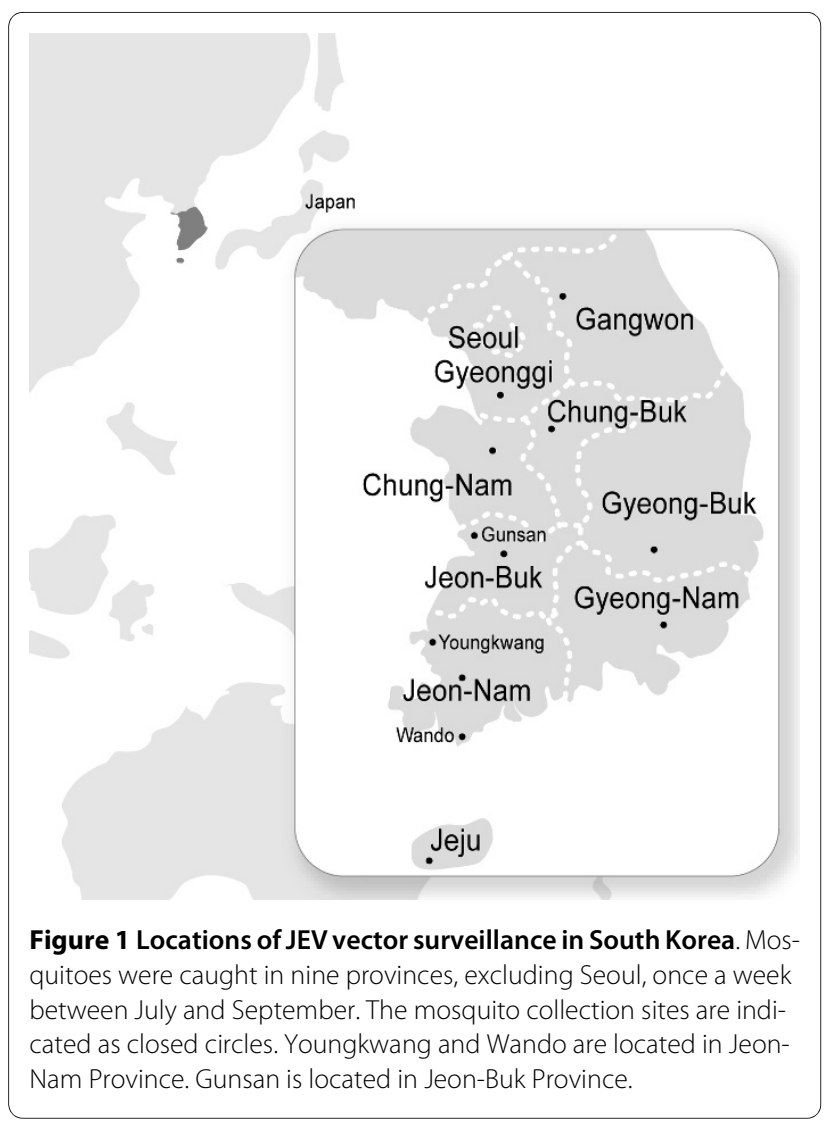

and Japan $[6,13,23]$. When phylogenetic analyses were performed, the branching patterns on both the $\mathrm{NJ}$ and ML trees were similar, with slight differences in the reliability indices. Thus, only ML tree is presented in this study (Figure 3). Most Korean strains were divided into genotypes 1 and 3 . Ten Korean strains grouped in genotype 3, together with those isolated in China, Japan, India, Philippines, Sri Lanka, and Vietnam between the $1930 \mathrm{~s}$ and the early $1990 \mathrm{~s}$. Another 10 Korean strains clustered in genotype 1, together with strains isolated in China, Japan, Thailand, and Vietnam between the late $1970 \mathrm{~s}$ and the present day. Historically, the genotypic classification of some JEV strains was discordant, depending on the phylogenetic markers or tree construction method used, including substitution models.

Two Korean JEV strains, K82P01 and K91P55, were notably problematic in phylogenetic analyses. K82P01 was grouped in genotype 3 or unclassified based on the $E$ gene sequence, and K91P55 was classified in either genotype 1 or genotype 3 depending on the gene region used for the phylogenetic analysis $[7,10,16]$. Moreover, in an analysis of Flavivirus recombination, K82P01 and K91P55 appeared to be putative recombinant strains derived from genotype 1 and 3 strains [24]. When we analyzed the two strains using the RDP3 program [25], both were shown to be recombinant strains (data not shown). Chuang and Chen recently provided experimen-

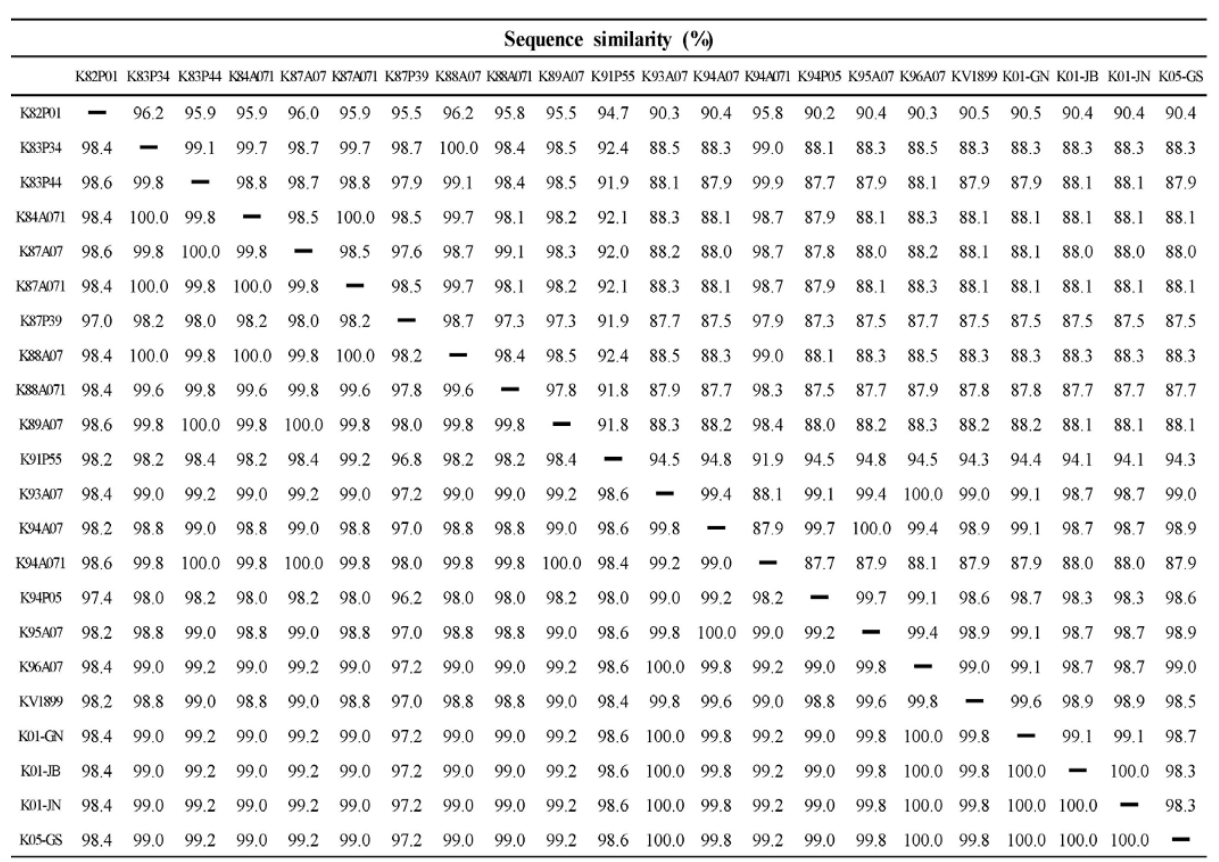

Figure 2 Nucleotide and amino acid sequence similarities among Korean JEV strains. The percentage similarities between the aligned nucleotide and deduced amino acid sequences were calculated (uncorrected p-distances) with the MegAlign program implemented in the Lasergene software. The nucleotide similarities (\%) are shown above the diagonal and the deduced amino acid identities (\%) are shown below the diagonal. 


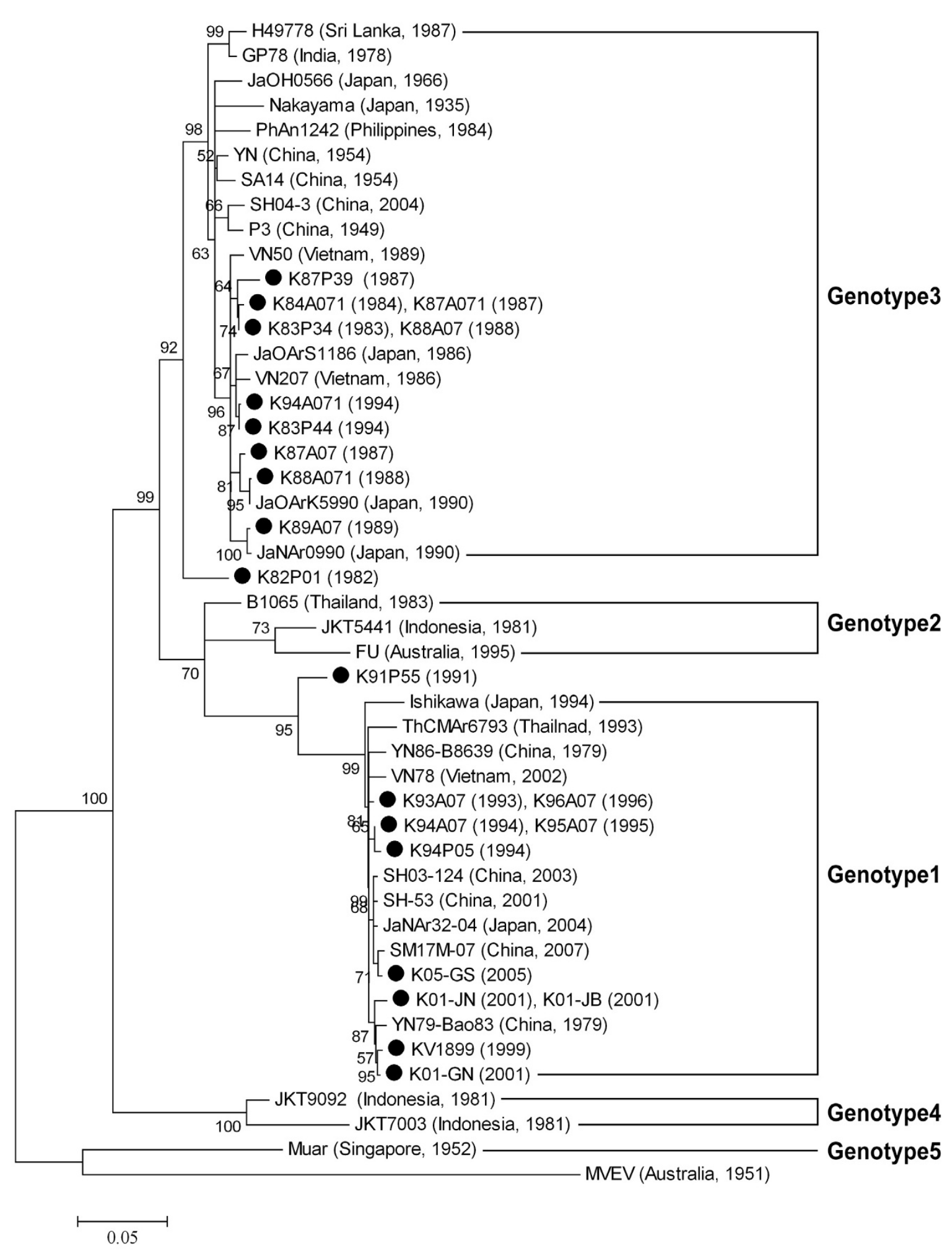

Figure 3 Maximum likelihood tree of $51 \mathrm{JEV}$ strains representing four different genotypes, including 22 Korean strains. The HKY85 evolutionary model of nucleotide substitution was used to construct a $\mathrm{ML}$ tree for the complete $\mathrm{E}$ gene sequence. The tree was rooted with the $\mathrm{E}$ gene sequence of the Murray Valley encephalitis virus (MVEV, accession no. NC_000943). Branch reliability is indicated with quartet puzzling (QP) values. Branches showing QP reliability > 70\% can be considered well supported [22]. The scale bar indicates the number of base substitutions per site. Korean strains are indicated as closed circles and the JEV genotypes are as defined previously [8]. 
tal evidence that RNA recombination occurs in JEV [26]. This genotypic conflict may be confirmed by sequencing the $\mathrm{E}$ gene again or, more effectively, the full genome.

However, in this study, we could not pursue this research because the two strains were lost during longterm storage. Therefore, we suggest that these two strains are not used in future studies of JEV evolution. Our results indicate that the genotypes of the Korean JEV strains changed from genotype 3 to genotype 1 around 1993, with both genotypes isolated in 1994 (Figure 3). Since then, only genotype 1 strains have been isolated in South Korea. Before the present study, it was reported that genotype 1 was introduced into Korea around 1991 (K91P55 strain) or 1994 (K94P05 strain) [14,15,27].

Interestingly, this genotype change was also reported in Japan in 1991 [12,23], in China in 1979 [13], in Vietnam in 2001 [9], and in Thailand in 1991 [14]. Although several explanations have been offered $[5,7,9]$, we believe that migrating water birds may be a major mediator of the new genotypes in these regions. Consistent with this suggestion, the cattle egret, black-crowned night heron, and little egret (the major JEV reservoir) are migratory species in at least the countries of Japan, Korea, and China $[28,29]$.

In summary, this study reports that at least two distinct genotypes of JEV have circulated in South Korea. Genotype 3 strains were predominant in Korea before 1993, when genotype 1 strain K93A07 was first isolated. The two genotypes were detected simultaneously in 1994 but since then, only genotype 1 has been isolated in South Korea.

\section{Competing interests}

The authors declare that they have no competing interests.

\section{Authors' contributions}

SMY performed the experiments and contributed to the preparation of the manuscript. JEC, SYK, JR, and WYC collected the specimens and contributed to the data analysis. YRJ and MGH contributed to the data analysis and the preparation of the manuscript. YEJ designed the study, performed the experiments, and prepared the manuscript. All authors have read and approved the final manuscript.

\section{Acknowledgements}

The authors thank all the researchers who have been engaged in the JE Epidemic Forecast Program since 1975 for their devotion to duty. Thanks are also due to Gi-Chang Bing at the Migratory Birds Center, National Park Research Institute, for providing information about Korean water birds. This research was undertaken with a grant from the National Institute of Health, Korea Centers for Disease Control and Prevention.

\section{Author Details}

WHO Japanese Encephalitis Regional Reference Laboratory for the Western Pacific Region/Division of Arboviruses, National Institute of Health, Korea Centers for Disease Control and Prevention, Seoul, Republic of Korea

Received: 26 April 2010 Accepted: 14 June 2010

Published: 14 June 2010

\section{References}

1. Vaughn DW, Hoke CH Jr: The epidemiology of Japanese encephalitis: prospects for prevention. Epidemiol Rev 1992, 14:197-221.

2. Chambers TJ, Hahn CS, Galler R, Rice CM: Flavivirus genome organization, expression, and replication. Annu Rev Microbiol 1990, 44:649-688.

3. Holland J, Spindler K, Horodyski F, Grabau E, Nichol S, VandePol S: Rapid evolution of RNA genomes. Science 1982, 215:1577-1585.

4. Chen WR, Tesh RB, Rico-Hesse R: Genetic variation of Japanese encephalitis virus in nature. J Gen Virol 1990, 71(Pt 12):2915-2922.

5. Chen WR, Rico-Hesse R, Tesh RB: A new genotype of Japanese encephalitis virus from Indonesia. Am J Trop Med Hyg 1992, 47:61-69.

6. Jan LR, Yueh YY, Wu YC, Horng CB, Wang GR: Genetic variation of Japanese encephalitis virus in Taiwan. Am J Trop Med Hyg 2000, 62:446-452.

7. Williams DT, Wang LF, Daniels PW, Mackenzie JS: Molecular characterization of the first Australian isolate of Japanese encephalitis virus, the FU strain. J Gen Virol 2000, 81:2471-2480.

8. Solomon T, Ni H, Beasley DW, Ekkelenkamp M, Cardosa MJ, Barrett AD: Origin and evolution of Japanese encephalitis virus in southeast Asia. $J$ Virol 2003, 77:3091-3098.

9. Nga PT, del Carmen Parquet M, Cuong VD, Ma SP, Hasebe F, Inoue S, Makino Y, Takagi M, Nam VS, Morita K: Shift in Japanese encephalitis virus (JEV) genotype circulating in northern Vietnam: implications for frequent introductions of JEV from Southeast Asia to East Asia. J Gen Virol 2004, 85:1625-1631.

10. Uchil PD, Satchidanandam V: Phylogenetic analysis of Japanese encephalitis virus: envelope gene based analysis reveals a fifth genotype, geographic clustering, and multiple introductions of the virus into the Indian subcontinent. Am J Trop Med Hyg 2001, 65:242-251.

11. Pyke AT, Williams DT, Nisbet DJ, van den Hurk AF, Taylor CT, Johansen CA, Macdonald J, Hall RA, Simmons RJ, Mason RJ, Lee JM, Ritchie SA, Smith GA, Mackenzie JS: The appearance of a second genotype of Japanese encephalitis virus in the Australasian region. Am J Trop Med Hyg 2001, 65:747-753.

12. Ma SP, Yoshida Y, Makino Y, Tadano M, Ono T, Ogawa M: Short report: a major genotype of Japanese encephalitis virus currently circulating in Japan. Am J Trop Med Hyg 2003, 69:151-154.

13. Wang HY, Takasaki T, Fu SH, Sun XH, Zhang HL, Wang ZX, Hao ZY, Zhang JK, Tang Q, Kotaki A, Tajima S, Liang XF, Yang WZ, Kurane I, Liang GD: Molecular epidemiological analysis of Japanese encephalitis virus in China. J Gen Virol 2007, 88:885-894.

14. Nitatpattana N, Dubot-Peres A, Gouilh MA, Souris M, Barbazan P, Yoksan S, de Lamballerie X, Gonzalez JP: Change in Japanese encephalitis virus distribution, Thailand. Emerg Infect Dis 2008, 14:1762-1765.

15. Nam JH, Chae SL, Won SY, Kim EJ, Yoon KS, Kim BI, Jeong YS, Cho HW: Short report: genetic heterogeneity of Japanese encephalitis virus assessed via analysis of the full-length genome sequence of a Korean isolate. Am J Trop Med Hyg 2001, 65:388-392.

16. Yun SI, Kim SY, Choi WY, Nam JH, Ju YR, Park KY, Cho HW, Lee YM: Molecular characterization of the full-length genome of the Japanese encephalitis viral strain K87P39. Virus Res 2003, 96:129-140.

17. Yang DK, Kim BH, Kweon CH, Kwon JH, Lim SI, Han HR: Biophysical characterization of Japanese encephalitis virus (KV1899) isolated from pigs in Korea. J Vet Sci 2004, 5:125-130.

18. Chung YJ, Nam JH, Ban SJ, Cho HW: Antigenic and genetic analysis of Japanese encephalitis viruses isolated from Korea. Am J Trop Med Hyg 1996, 55:91-97.

19. Nam JH, Chung YJ, Ban SJ, Kim EJ, Park YK, Cho HW: Envelope gene sequence variation among Japanese encephalitis viruses isolated in Korea. Acta Virol 1996, 40:303-309.

20. Thompson JD, Gibson TJ, Plewniak F, Jeanmougin F, Higgins DG: The CLUSTAL_X windows interface: flexible strategies for multiple sequence alignment aided by quality analysis tools. Nucleic Acids Res 1997, 25:4876-4882

21. Tamura K, Dudley J, Nei M, Kumar S: MEGA4: Molecular Evolutionary Genetics Analysis (MEGA) software version 4.0. Mol Biol Evol 2007, 24:1596-1599.

22. Schmidt HA, Strimmer K, Vingron M, von Haeseler A: TREE-PUZZLE: maximum likelihood phylogenetic analysis using quartets and parallel computing. Bioinformatics 2002, 18:502-504. 
23. Nerome R, Tajima S, Takasaki T, Yoshida T, Kotaki A, Lim CK, Ito M, Sugiyama A, Yamauchi A, Yano T, Kameyama T, Morishita I, Kuwayama M, Ogawa T, Sahara K, Ikegaya A: Molecular epidemiological analyses of Japanese encephalitis virus isolates from swine in Japan from 2002 to 2004. J Gen Virol 2007, 88:2762-2768.

24. Twiddy SS, Holmes EC: The extent of homologous recombination in members of the genus Flavivirus. J Gen Virol 2003, 84:429-440.

25. Martin D, Rybicki E: RDP: detection of recombination amongst aligned sequences. Bioinformatics 2000, 16:562-563.

26. Chuang CK, Chen WJ: Experimental evidence that RNA recombination occurs in the Japanese encephalitis virus. Virology 2009, 394:286-297.

27. Nitatpattana N, Apiwathnasorn C, Barbazan P, Leemingsawat S, Yoksan S, Gonzalez JP: First isolation of Japanese encephalitis from Culex quinquefasciatus in Thailand. Southeast Asian J Trop Med Public Health 2005, 36:875-878

28. Yamashina Institute for Ornithology: Atlas of Japanese migratory birds from 1961 to 1995. Japan, Bird Migration Research Center 2002.

29. Park JG, Seo JH: Guide for Korean wild birds (water birds). Korea, Shingubook 2008.

30. Hasegawa H, Yoshida M, Fujita S, Kobayashi Y: Comparison of structural proteins among antigenically different Japanese encephalitis virus strains. Vaccine 1994, 12:841-844.

doi: $10.1186 / 1743-422 X-7-127$

Cite this article as: Yun et al., Molecular epidemiology of Japanese encephalitis virus circulating in South Korea, 1983-2005 Virology Journal 2010, 7:127

Submit your next manuscript to BioMed Central and take full advantage of:

- Convenient online submission

- Thorough peer review

- No space constraints or color figure charges

- Immediate publication on acceptance

- Inclusion in PubMed, CAS, Scopus and Google Scholar

- Research which is freely available for redistribution

Submit your manuscript at www.biomedcentral.com/submit
C) Biomed Central 